\title{
Formação de pesquisadores em educação no Brasil, o papel das agências e a educação básica
}

Remi Castioni

\section{Resumo}

Este texto contempla uma discussão sobre o processo de distribuição das Bolsas de Produtividade em Pesquisa do CNPq e se sustenta em uma descrição sobre a evolução dos programas de pós-graduação no país, em particular, na área de educação. Com isso, problematiza a contribuição desses programas para a educação básica e identifica que uma das formas de estimular essa relação é o sistema de Bolsas de Produtividade. No entanto, a escassa transparência sobre o processo de distribuição dessas bolsas e sua excessiva concentração em determinadas regiões do país corroboram para a defesa de reforçar o papel dos grupos de pesquisa e a redefinição de novos critérios de seleção dessas bolsas, considerando as demandas do novo Plano Nacional de Educação.

Palavras-chave: Pesquisa em educação. Bolsa de produtividade. Educação básica. Pós-graduação.

\section{Apresentação}

A formação de professores tem sido um tema recorrente na literatura brasileira. O assunto é um dos principais desafios do novo Plano Nacional de Educação (BRASIL, 2014a). E um dos elementos que sustenta essa relevância, no Brasil, é a expansão da oferta de vagas no Ensino Superior, sobretudo nos cursos de Pedagogia, um dos quatro cursos mais representativos dentre os outros cursos.

Percebemos também que os atuais desafios da educação básica - formação de professores, abandono escolar, ausência de identidade do Ensino Médio, repetência e baixo desempenho de estudantes em avaliações, etc. - corroboram para essa discussão. Embora seja tema de grande interesse da sociedade, o desempenho 
da educação básica brasileira tem deixado a desejar quando se compara as recentes avaliações.

Nunca se falou tanto em melhorar a educação brasileira como nos dias atuais. $\mathrm{O}$ catalisador desse processo é, sem dúvida, o novo Plano Nacional de Educação (PNE), que determinou metas específicas para a melhoria dos indicadores de educação e de formação de professores.

E é a partir desse cenário que objetivamos refletir sobre a contribuição dos programas de pós-graduação em educação e sua relação com a educação básica. Visto que a formação stricto sensu é requisito básico para o ingresso na carreira docente universitária - e que estes docentes, por sua vez, são formadores de futuros docentes da educação básica. Nesse sentido, centramos nossa discussão sobre a distribuição das Bolsas de Produtividade em Pesquisa do Conselho Nacional de Desenvolvimento Científico e Tecnológico (CNPq) e as problemáticas da educação básica. Em face de ausência de dados e visibilidade do perfil de tais bolsistas, não é possível alcançar uma análise mais aprofundada sobre essa correlação.

Para tanto, estruturamos o texto em seis seções. Na primeira seção, tecemos considerações iniciais, onde contextualizamos a problemática da relação formação stricto sensu e a educação básica, e a evolução do Plano Nacional de Pós-Graduação. Na segunda seção, abordamos sobre a complexidade e os desafios da educação básica e a demanda de formação de professores. Enquanto na terceira seção, fazemos uma análise, a partir de dados estatísticos, acerca da expansão das universidades e a formação de recursos humanos na área da educação, no Brasil. Na quarta, damos início à análise sobre a oferta de Bolsas de Produtividade em Pesquisa do CNPq, doravante denominada de BP, onde apresentamos uma reflexão em torno dos critérios de seleção dos referidos bolsistas. Dando continuidade a essa análise, na quinta seção, abordamos sobre a BP do CNPq, no caso específico do Comitê Assessor de Educação - CA-Educação, e pontuamos as disparidades na oferta de bolsas para essa área, em relação às demais. Concluímos com algumas considerações (sexta seção) que corroboram com a ideia de evidenciar contradições na oferta da BP do CNPq, bem como seu papel para a melhoria da educação básica.

\section{Um breve panorama da pós-graduação no Brasil}

Discorrer sobre a oferta de cursos stricto sensu e sua relação com a educação básica demanda abordar uma série de elementos - desde o processo histórico dessa oferta, bem como a apresentação das diferentes ofertas. Consideramos 
relevante, nessa reflexão, a oferta de Bolsas de Produtividade em Pesquisa do CNPq. Para tanto, faz-se necessário tecer como elemento preliminar a evolução do Plano Nacional de Pós-Graduação no Brasil.

Considerando a plena vigência do VI Plano Nacional de Pós-graduação - PNPG (2011-2020), é possível inferir um resultado positivo em sua evolução, desde o primeiro plano lançado pela Coordenação de Aperfeiçoamento de Pessoal de Nível Superior (CAPES), em 1975, aos dias atuais. Nessa sequência, tivemos o I PNPG, entre 1975 e 1979; o II PNPG, entre 1982 e 1985; o III PNPG, entre 1986 e 1989. Embora autores como Cury (2005, p. 18) justifiquem que o IV PNPG de fato não ocorreu; e somente tivemos a retomada do PNPG efetivo, com o V Plano (1996-2010).

Nestes 50 anos de trajetória da pós-graduação, cujo marco foi a regulamentação do Parecer $n^{\circ}$ 977, de 3 dezembro de 1965, do então Conselho Federal de Educação (CONSELHO FEDERAL DE EDUAÇÃO, 1965), o Brasil duplicou o número de programas de mestrado e doutorado, quadruplicou o número de títulos de mestrado concedidos e quintuplicou o número de doutores formados pelas universidades brasileiras (BRASIL, 2010; CGEE, 2012).

Dessa forma, os Planos Nacionais de Pós-Graduação cumpriram importante papel na formação da infraestrutura de pesquisa e da pós-graduação no Brasil. Apesar do esforço empreendido pelos quase 3 mil programas de mestrado e 1,5 mil de doutorado, ainda estamos longe da média mundial na formação de doutores.

Sobre esse aspecto, os últimos dados disponíveis, com base na coleta CAPES (encerrada em 2009), demonstram que formamos 42 mil mestres (Figuras 3 e 4) e 12 mil doutores (CGEE, 2012). Entretanto, formamos 10 doutores por $100 \mathrm{mil}$ habitantes, enquanto a média mundial é de 200. Países como Alemanha e Suíça formam 500 doutores (DUTTA; LANVIN, 2013). Para alcançar a média mundial, mantida a taxa de expansão de $11 \%$ ao ano, o Brasil levará quase 30 anos para alcançar o patamar de países desenvolvidos.

Os dados do censo demográfico de 2010 revelam que, entre a população com 10 anos ou mais, menos de $0,5 \%$ da população tem título de mestre ou doutor, e no outro extremo, 2/3 da população brasileira têm até o Ensino Fundamental. Essa é uma realidade ainda muito distante dos padrões internacionais. Em 2010, tínhamos 517 mil mestres e 187 mil doutores, e a taxa de ocupação de ambos os titulados beiravam os $90 \%$ (IBGE, 2012). 
A área de Humanas é a que mais forma mestres no Brasil; e no que diz respeito à formação de doutores, essa área está em segundo lugar, atrás, apenas, da área de Ciências da Saúde. Entre os mestres formados na área de Humanas, quase a metade provém da área de educação; e entre os doutores, mais de $1 / 3$ pertence à área da educação (CGEE, 2010, 2012). Esses dados evidenciam a importância da área de Educação entre os programas de formação de recursos humanos, bem como permitem questionar sobre a efetividade da mesma para um nível formativo que mais demanda inovação - a educação básica.

E ainda sobre a trajetória da pós-graduação no Brasil, podemos constatar que os dados compilados pelo Centro de Gestão e Estudos Estratégicos - CGEE (2010) demonstram ainda que: i) quase um terço dos mestres e dos doutores brasileiros reside no Estado de São Paulo; ii) o número de mestres e de doutores por mil habitantes é maior no Distrito Federal e no Rio de Janeiro; ii) a população de mestres e doutores é muito mais branca do que a população total; iii) a proporção de mestres que têm emprego formal na educação é muito menor do que a de doutores; iv) as mulheres são maioria entre os mestres, mas têm remuneração inferior. Esses elementos apontam indicadores significativos, dos últimos anos, no sistema de pós-graduação. Entretanto, há que se questionar sobre a contribuição dessa formação para a educação básica, tendo em vista a ausência de dados que revelem uma relação direta entre esse processo e melhorias nos indicadores educacionais, estabelecidos em avaliações nacionais e internacionais (PISA, IDEB, SAEB e ENEM) ${ }^{1}$.

É válido salientar que há iniciativas importantes, como os programas recentes (como: OBEDUC, PIBID, PARFOR, LIFE, PRODOCÊNCIA) da CAPES, que caminham na direção de aproximar a escola das universidades e do sistema de pós-graduação, visando à formação de professores.

Historicamente, o esforço da CAPES sempre esteve dirigido à formação de recursos humanos para o Ensino Superior. É possível deduzir que esse direcionamento ainda representa um conjunto de ações com farta distribuição de bolsas, mas sem evidência de mecanismos para aferição de resultados que demonstrem, de fato, a contribuição do sistema de formação de pesquisadores - no caso, a universidade brasileira e os 225 programas de pós-graduação em educação - e sua vinculação à educação básica e à formação de professores.

1 Programme for International Student Assessment (PISA) - programa internacional de avaliação de estudantes, criado pela Organização para a Cooperação e Desenvolvimento Econômico, em 2000; Índice de Desenvolvimento da Educação Básica (IDEB), criado pelo Instituto Nacional de Estudos e Pesquisas Educacionais Anísio Teixeira, em 2007; Sistema de Avaliação da Educação Básica (SAEB), criado pelo Instituto Nacional de Estudos e Pesquisas Educacionais Anísio Teixeira, em 1990, sendo que atualmente responde pelo nome de Avaliação Nacional da Educação Básica (Aneb) e Exame Nacional do Ensino Médio (ENEM), criado em 1998. 
No que diz respeito ao resultado das pesquisas de programas stricto sensu em educação, André (2010, p.179) afirma que 30\% dos resumos de dissertações e teses sobre formação de professores, defendidas em 2007, não contemplavam qualquer menção aos resultados da pesquisa; segundo a autora, essa lacuna pressupõe ausência de resultados ou dificuldades do pesquisador em delimitar aspectos metodológicos e expressar resultados.

Outra questão identificada sobre a formação stricto sensu é a escassa evidência sobre a vinculação de projetos dos estudantes aos grupos de pesquisa das universidades, ou seja, desvinculação dessas pesquisas a um plano estratégico de melhoria da educação básica.

Os indicadores quantitativos da educação básica melhoraram muito nos últimos anos, fato que tem sido reconhecido por organismos internacionais como a Organização das Nações Unidas (ONU) e a Organização para Cooperação e Desenvolvimento Econômico (OCDE). E sobre os indicadores qualitativos, que dizem respeito ao aprendizado, existem dados que demonstram o desempenho dos estudantes da educação básica (VELOSO, 2009, p. 3).

E sobre essa questão, é válido salientar que o Senado Federal promoveu, em 2012, uma série de audiências públicas com o intuito de tratar problemáticas concernentes à educação básica, quando se constatou a persistência de indicadores com baixo desempenho estudantil (BRASIL, 2013a).

Nesse sentido, essa reflexão vai ao encontro de problematizar um dos importantes mecanismos de promoção da pesquisa no Brasil. E apesar de vislumbrar uma luz ao final do túnel, com a determinação de que a CAPES passaria a dirigir também a formação de professores para a educação básica, determinação atribuída a partir da Lei ${ }^{\circ} 11.502$, de 11 de julho de 2007 (BRASIL, 2007), entre suas atribuições, até então restritas ao Ensino Superior, centramos atenção em outro sistema de bolsas, aquelas ofertadas pelo CNPq.

Embora o CNPq disponha de $1 / 4$ das bolsas disponíveis na CAPES, para a formação de mestres e doutores, a formação para a pesquisa é notadamente financiada pelo CNPq. Por isso, analisaremos, particularmente, uma das bolsas disponíveis para essa finalidade, a Bolsa de Produtividade em Pesquisa (PQ) no âmbito do Comitê Assessor de Educação. Entretanto, para mergulhar nessa análise, é preciso considerar primeiro a expansão das universidades federais e a formação de recursos humanos para a educação no país. Nesse sentido, é válido ressaltar que existem outras iniciativas, em curso, que buscam vincular 
o sistema de fomento à pesquisa e sua contribuição para a educação; e, nessa direção, há um esforço sendo promovido por um conjunto de pesquisadores (GATTI et al., 2015).

\section{Expansão das universidades e formação de recursos humanos para a educação no Brasil}

Antes de centrar atenção sobre as ofertas formativas de pessoal para a pesquisa, precisamos considerar, a princípio, que a expansão recente da universidade pública brasileira, iniciada em 2007, com o Plano de Desenvolvimento da Educação (PDE) e o Programa de Apoio a Planos de Reestruturação e Expansão das Universidades Federais (REUNI), tem dado contribuição relevante para a ampliação da pós-graduação nas universidades federais. Embora não tenhamos dados estatísticos para confirmar, é possível deduzir que as universidades que aderiram ao REUNI se beneficiaram dessas condições para expandir seus respectivos programas de pós-graduação. Isso ocorreu com a efetivação dos planos de expansão e a contratação de mais de 25 mil professores ingressando nas universidades federais nos últimos anos, a maioria deles com título de doutor.

A expansão da rede federal produziu dois impactos relevantes - aumento na oferta de vagas para graduação e uma maior possibilidade de acesso à formação stricto sensu. No que diz respeito aos reflexos dessa expansão para os cursos de graduação, na Figura 1 demonstramos o número de vagas dos quatro principais cursos de acesso às universidades brasileiras e, que juntos, representam $30 \%$ do total.

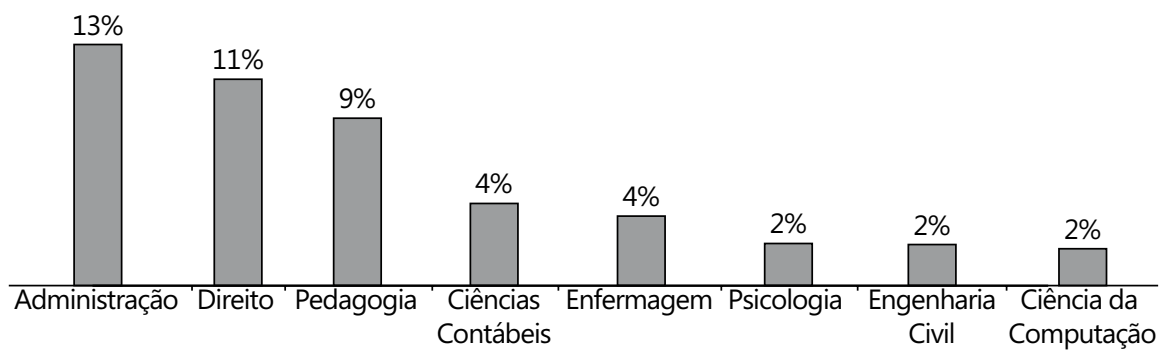

Fonte: Censo da Educação Superior, INEP (BRASIL, 2012).

Figura 1. Percentual de participação das matrículas dos oito primeiros cursos na educação superior no Brasil (2012).

Constatamos que, no caso das universidades federais, o maior número de vagas ficou concentrado nos cursos de Pedagogia, dado que remete à necessidade de 
formação de novos mestres e doutores na área de educação. A própria abertura de novos cursos de mestrado e doutorado também é impulsionada por essa disponibilidade de mestres e doutores formados e atuantes nas Faculdades de Educação - corroborando tanto para novos campi, na expansão das próprias universidades existentes, quanto para a ampliação dos programas de pós-graduação em educação.

Além disso, constatamos que, no período de 2004-2012, o número de matrículas no curso de Pedagogia foi, em geral, maior que nos outros cursos - embora tenha experimentado uma queda entre 2004 e 2009 -, diferentemente dos demais cursos, que, em 2009, chegaram a ultrapassar o curso de Pedagogia (Figura 2).

A partir do referido ano, com o efeito da maturação do REUNI e, consequentemente, com a implantação do Plano Nacional de Formação de Professores da Educação Básica (PARFOR), em regime de colaboração entre a CAPES, Estados, municípios, Distrito Federal e as Instituições de Educação Superior, as matrículas do curso de Pedagogia voltaram a ultrapassar os demais cursos.

Evolução dos Números de Matrículas em Universidades Federais

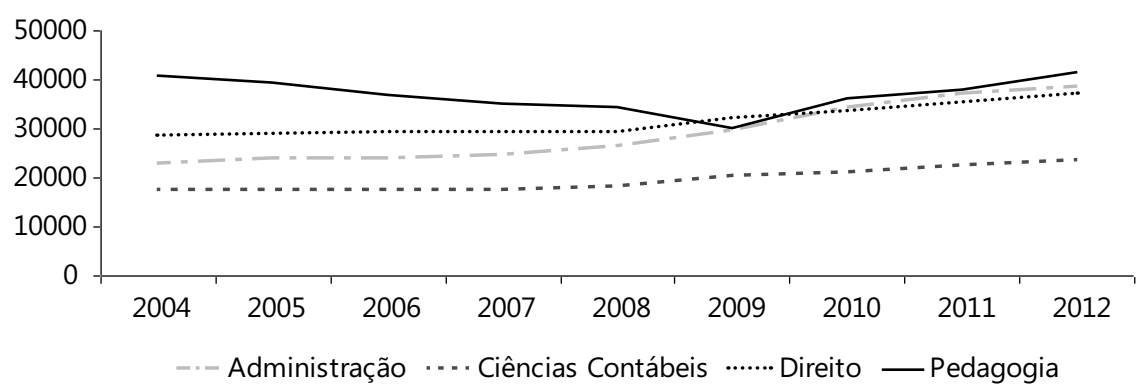

Fonte: Censo da Educação Superior, INEP (BRASIL, 2012).

Figura 2. Matrículas nos principais cursos ofertantes nas universidades federais.

No que diz respeito ao acesso à formação stricto sensu, analisamos essa oferta de acordo com a dependência administrativa, ou seja, onde se formam os mestres e doutores no Brasil. Na Figura 3, é possível constatar que, a partir de 2007, os cursos da área federal consolidaram-se como o principal espaço para a formação de doutores. 


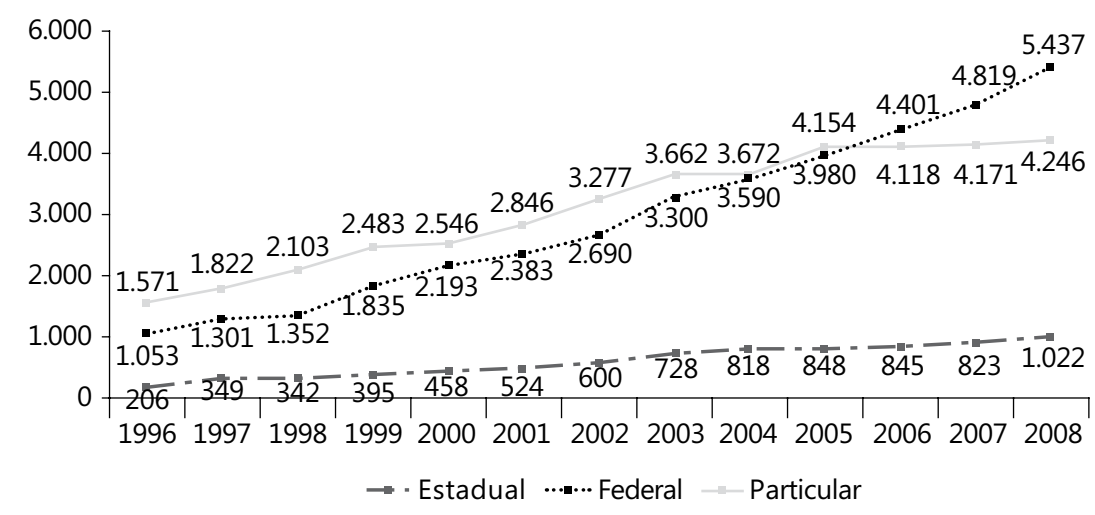

Fonte: CGEE, 2010.

Figura 3. Oferta de doutorado por esfera administrativa no Brasil.

A melhoria e a estabilização na fonte de financiamento das universidades federais permitiram elevar a participação no segmento federal, tanto nas matrículas como nos programas de pós-graduação .

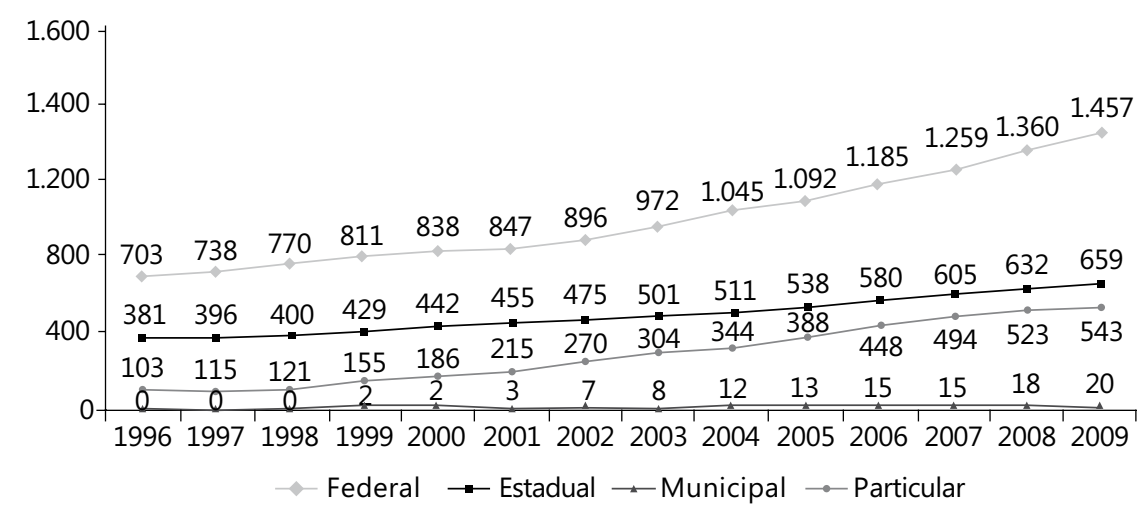

Fonte: CGEE, 2012.

Figura 4. Onde são formados os mestres no Brasil.

Nesse sentido, podemos avaliar que, com quase $70 \%$ de doutores, as universidades federais representam o espaço privilegiado de formação de pesquisadores no Brasil. Boa parte da renovação da universidade brasileira foi fruto, nos últimos anos, a partir do REUNI, dos concursos públicos que atraíram um considerável contingente de egressos dos programas de pós-graduação dessas universidades. Os dados da Tabela 1 demonstram a inversão que ocorreu nos recursos humanos das universidades federais. Em 
2006, por exemplo, os professores com título de graduação representavam 1/5 do total da força de trabalho, e os doutores, menos da metade. Atualmente, os graduados são menos de $2 \%$, e os doutores, mais de $2 / 3$.

Tabela 1. Docentes e titulação nas universidades federais brasileiras.

\begin{tabular}{lcc}
\hline Titulação & Docentes & Participação \\
\hline Graduação & 1.304 & 1,84 \\
Aperfeçoamento & 42 & 0,06 \\
Especialista & 2.511 & 3,55 \\
Mestre & 17.549 & 24,8 \\
Doutor & 49.354 & 69,75 \\
\hline Total & 70.760 & 100,00 \\
\hline
\end{tabular}

Fonte: Boletim Estatístico de Pessoal - Ministério do Planejamento, BOLETIM estatístico..., 2012).

Através do Boletim Estatístico de Pessoal foi possível constatar que houve um maior acesso à formação stricto sensu; e que, em março de 2013, os docentes com graduação representavam 1.304, enquanto os mestres eram 17.549, e os doutores 49.354 (BOLETIM estatístico..., 2014).

Considerando que os programas de mestrado já eram maioria, entre as instituições federais que formam mestres, podemos supor que a contribuição do REUNI favoreceu as condições para que essa expansão se consolidasse nas universidades federais avançando sobre os programas de doutorado. Os dados mostram que a expansão dos cursos de mestrado e de doutorado são simétricos. Dessa forma, houve uma importante inflexão, a partir dos anos de 2007 e 2008, na pós-graduação brasileira na área da educação.

A esse respeito, Macedo e Sousa (2010) mencionam sobre a importância que os programas de pós-graduação em educação assumiram ao longo dos anos, demonstrando, assim, o reconhecimento dos mesmos, em comparação com as demais áreas.

Analisando os dados da coleta CAPES de 2009, as autoras reiteram o destaque que a área de Educação assumiu. Entretanto, se dividem quanto à contribuição que esses programas têm dado como resposta a educação básica. Da mesma forma, Menezes (2012) observa que não houve uma convergência entre essa expansão e a formação de professores para a educação básica, uma vez que se priorizou no sistema a formação para a pesquisa. 
Na avaliação de Macedo e Sousa (2010), o dilema persiste quando se comparam o desempenho da educação aos padrões das demais áreas. O reconhecimento, segundo elas, se dá na comparação aos demais programas de pós-graduação e, nesse sentido, com os parâmetros que estes desenvolveram e não com relação à efetiva contribuição para a educação básica (Idem).

Uma aproximação sobre essa temática foi dada por Hostins (2013) ao comparar os principais programas de pós-graduação no Brasil. Nas suas conclusões, apresentou um quadro a partir de uma análise das disciplinas que remetem à formação de pesquisadores em educação dos programas de excelência, conforme classificação da autora. Concluiu que há pouca expressão nesse percurso dos temas inerentes à educação básica, que são substituídos por problemáticas que não tem a realidade como lócus. Ao se enredar em categorias de análise presas a esquemas pré-determinados no campo das ciências, o debate sobre os problemas educacionais passa ao largo dos principais programas de formação de pesquisadores da área da educação. Nesse sentido, inserir a discussão sobre o processo de acesso a Bolsas de Produtividade em Pesquisa do CNPq reascende o debate em torno da contribuição da formação de pesquisadores para a educação básica. Sobretudo, porque na atualidade, a formação de professores da educação básica também contempla a escola como locus de pesquisa e formação (MENEZES, 2012; NÓVOA, 2013). Nesse sentido, a escola passa a ser um espaço de formação e de pesquisa em relação direta com a universidade, e como mecanismo de valorização dos saberes desses docentes/pesquisadores, de fixação dos mesmos em seus estabelecimentos de ensino, e de cooperação para a formação em exercício de novos professores.

\section{Educação Básica, complexidade e desafios}

Os desafios e complexidades da educação básica têm impulsionado o ingresso de professores em programas de pós-graduação stricto sensu. E para entender essa relação, é preciso explicitar algumas questões relevantes sobre esse nível de ensino. Nesse sentido, é válido mencionar, a princípio, que a educação básica, conforme prevê a Lei de Diretrizes e Bases da Educação Nacional - LDB, nº 9.394/96 (BRASIL, 1996), se subdivide em: Educação Infantil, Ensino Fundamental, Ensino Médio e as diferentes modalidades de ensino.

Essa organização permite entender que o território brasileiro apresenta uma significativa diversidade que demanda uma política educativa de valoração das características e particularidades de sua população. Desta forma, dar conta de uma oferta educativa, considerando a heterogeneidade de necessidades e de ofertas formativas, constitui-se em enorme desafio. 
Aproximar os programas de pós-graduação em educação das demandas da educação básica, revelada tanto pelos indicadores de acesso como de desempenho, demonstra a necessidade de uma conexão entre a universidade brasileira - sobretudo, seu sistema de pós-graduação -, com aquele nível de ensino. Sobre essa questão, Menezes (2012) afirma que existe uma cultura de distanciamento entre a universidade e a educação básica; e que a insuficiente articulação entre essas duas esferas de ensino compromete a formação inicial dos professores e dificulta a formação permanente dos já graduados.

Sobre essa temática, é possível identificar uma série de desafios sintetizados na fala de Soares (2014, p. 445):

[...] o primeiro movimento parte da afirmação da necessidade de aproximar as pesquisas em educação do trabalho de formação inicial dos professores; o segundo, parte de movimento oposto, mas não contrário, ou seja, da necessidade de aproximar a formação inicial dos professores das pesquisas em educação [...].

Nessa mesma linha de pensamento, o autor argumenta que nunca se investiu tanto em educação, nunca se formaram tantos mestres e doutores, entretanto, isso não tem sido refletido na melhoria dos indicadores educacionais brasileiros, que continuam apresentando baixo desempenho quando comparados tanto entre escolas dentro do próprio país, como internacionalmente.

Ao comparar as diferenças entre o que se passa com o nível superior e a educação básica, Soares (2014) afirma que o planejamento de longo prazo, que beneficiou a pós-graduação brasileira, não foi apropriado pela educação básica. Portanto, sem pretender adentrar nas particularidades de cada um dos níveis e ofertas da educação básica e da diversidade de seus desafios, centramos a atenção em algumas questões inerentes ao Ensino Médio, onde se encontram os maiores desafios dessa etapa de formação, dado o elevado número de jovens na idade escolar apropriada que não estão matriculados.

O Ensino Médio tem como finalidade o desenvolvimento do individuo, assegurando-lhe a formação comum indispensável para o exercício da cidadania, fornecendo-lhe possibilidades para ingressar no mundo laboral e prosseguir nos seus estudos. Entretanto, essa oferta formativa resguarda uma história de intenso debate em torno de sua identidade - educação propedêutica ou formação profissional. Nesse sentido, foi instituído, como uma das possibilidades de mudança no Ensino Médio, o Ensino Médio Inovador, uma iniciativa para superação de tal 
dicotomia (FERREIRA, 2014, p. 143), que propõe uma educação geral, tendo a categoria trabalho como princípio educativo.

Dessa forma, o Ensino Médio está organizado, atualmente, em diferentes possibilidades de oferta: Ensino Médio, Ensino Médio Inovador, Ensino Médio articulado às diferentes modalidades - educação profissional, educação de jovens e adultos, educação no campo e educação indígena -, que compõem um leque de ofertas. Entretanto, carece de uma formação de professores para atender a essa diversidade. Essa assertiva se constata pela ausência da temática do Ensino Médio nos grupos de pesquisa da Associação Nacional de Pós-Graduação e Pesquisa em Educação (ANPED).

Independentemente da forma de organização dessa etapa de ensino, entendemos que o Ensino Médio enfrenta desafios educacionais e problemáticas - problemáticas estas recorrentes e/ou atuais. Dentre as recorrentes, se insere a defasagem idade/série, o absenteísmo e o abandono escolar; além de temas atuais como: bullying, intolerância de gênero, violência no espaço educativo e formação de professores que, na atualidade, volta a ser o centro das atenções. E sobre essa problemática, Gatti $(2012,2013,20124)$ analisa a influência da questão para a educação básica, enquanto Cunha (2012) afirma que a qualidade da formação docente é uma das temáticas que se destaca como mais importante nas pesquisas.

Dentre as problemáticas relacionadas que, também, vêm demandando discussão é a questão do abandono escolar no Ensino Médio. Essa dimensão carece de certa explicitação e de uma delimitação conceitual. Entretanto, é possível mencionar que se associa à interrupção da frequência ao sistema educativo na medida em que isso configura-se um regresso praticamente irreversível (JUSTINO, 2010).

E em função dessa e de outras questões, em dezembro de 2014, foi aprovada pela Comissão Especial da Câmara de Deputados o Projeto de Lei n ${ }^{\circ} 6.840$ (BRASIL, 2013b), que propõe modificações neste nível de ensino - mas que não conta com grande consenso entre os pesquisadores. Trata-se de uma política educativa e, enquanto tal, reflete diferentes conjunturas histórico-sociais e partidárias e um jogo de forças (SILVA, 2014).

As questões levantadas têm sido objeto de estudo e inspiração para o ingresso de professores em programas de pós-graduação stricto sensu. Nesse sentido, indagamos sobre que formação seria necessária para um desempenho 
profissional compatível para atender a essas problemáticas. Para tanto, faz-se necessária uma política educativa que contemple uma remuneração atrelada ao perfil e atuação do professorado, a expansão da oferta de cursos de graduação, perpassando por uma maior oferta e distribuição de bolsas de pós-graduação stricto sensu para os professores, sobretudo os que atuam na educação básica, dentre outros aspectos.

Além disso, constatamos que em uma consulta realizada junto aos programas de pós-graduação, 1/5 dos alunos informaram que eram professores da educação básica (MARTINS, 2012). A baixa remuneração desses alunos (salário médio entre R\$ $1.000,00$ e R $\$ 1.500,00$ ) evidencia outra problemática, a possível fixação dos mesmos nas redes de educação básica. Além disso, menos de 10\% declararam ter algum apoio para participação nesses programas de pós-graduação. Sem dúvida, para além da formação dos professores, uma remuneração mais condizente com esse segmento é de fundamental importância para incentivar melhorias na educação básica.

\section{Bolsas de Produtividade em Pesquisa do CNPq (PQ)}

A PQ do CNPq é uma dentre as mais de 12 possibilidades de bolsas individuais do sistema de Ciência, Tecnologia e Inovação (CT\&I) e as várias ofertas formativas para pesquisadores brasileiros. No orçamento de 2012, a dotação para a ação 0900 (Concessão de Bolsas de Estímulo à Pesquisa) foi de R \$ 235 milhões, valor inferior ao previsto para a ação Ciência sem Fronteiras, com orçamento de $\mathrm{R} \$ 255$ milhões a cargo do CNPq. No entanto, essa oferta apresenta um modo diferenciado quanto ao seu processo seletivo. A cada início de ano, pesquisadores vasculham o sítio da internet do CNPq para verificar o resultado de meses de espera dos seus pedidos de bolsa.

Considerando nossa experiência e contato frequente com uma rede de docentes, por ocasião da divulgação dos resultados dessa bolsa, no ano de 2013, os perfis de vários professores nas redes sociais sinalizavam uma insatisfação com esse processo seletivo. Um dos mais enfáticos manifestos contra esse resultado foi o da professora Suzana Herculano Houzel, publicado em seu blog e, posteriormente, no Jornal da Ciência. De modo geral, os comentários destacam que o CNPq se vale de critérios muito pouco transparentes, de listas já prontas e onde há muito pouco espaço para ascensão de novos pesquisadores. Alguns comentaram que, após anos de tentativa, a resposta padrão do CNPq tem sido: “[...] sua proposta [...] teve o seu mérito reconhecido. No entanto, na análise comparativa com as 
demais propostas, o seu pedido não alcançou classificação que permitisse o atendimento" (HOUZEL, 2013, p. 1).

De fato, as informações disponíveis na página eletrônica do CNPq apresentam poucos detalhes sobre os beneficiários. Depois da divulgação dos resultados, é difícil saber quem de fato continua no sistema ou não. Não se sabe ao certo quantos recebem bolsas, quantos estão classificados como Sênior, ou Pesquisador 1 ou 2, que projetos estão sendo apoiados e sua duração. A única informação confiável é buscar no currículo Lattes de cada pesquisador contemplado e saber qual de fato tem sido a contribuição. Rastrear milhares de currículos a partir do nome do beneficiário não é tarefa fácil.

Há uma escassez de estudos sobre a importância das Bolsas de Produtividade em Pesquisa, e de sua relação para a produção científica como para a formação de recursos humanos, por exemplo. Em um dos estudos sobre esse tema, os autores concluem que há uma forte correlação na concessão das bolsas quando se comparam os resultados bibliométricos, mas que colocam em dúvida o que de fato se espera de um pesquisador com bolsa de produtividade (WAINER; VIEIRA, 2013).

\section{Bolsas Produtividade em Pesquisa do CNPq: o caso da CA-Educação}

Considerando a escassez de dados sobre os critérios utilizados para seleção dos bolsistas, empreendemos um exercício no sentido de identificar o percentual de aprovados na bolsa de produtividade. Com isso, iniciamos monitoramento sobre o fluxo de bolsas no sistema nos últimos anos, e cujos dados foram obtidos em consultas realizadas no próprio Portal do $\mathrm{CNPq}$, e cotejadas com outras informações do Sistema CAPES. Nesse sentido, esses dados representam um esforço para compilar informações armazenadas quando da divulgação dos resultados das BP e das consultas ao Diário Oficial da União.

Recentemente, quando da reorganização do Portal do CNPq, foi possível visualizar melhor os resultados, mas só conseguimos realizar a consulta a partir do nome do candidato e da instituição. As bolsas de PQ totalizam 14 mil e consomem R\$ 191 milhões (BRASIL, 2014b), e se distribuem entre as diferentes áreas de conhecimento (Física, Matemática, Educação, etc.). Ou seja, $81 \%$ do orçamento destinado à rubrica, estímulo à pesquisa, é destinado às bolsas individuais de produtividade. 
No que diz respeito às bolsas do Comitê Assessor de Educação (CA-Educação) constatamos, por exemplo, que ela ocupa o $7^{\circ}$ lugar, com uma participação na faixa de 3\% do total da oferta nessa modalidade de bolsa, que é a metade da representação do CA-Física e CA-Astronomia, que possuem, ativas, aproximadamente 900 bolsas. Entretanto, é válido ressaltar que, nos últimos anos, cresceu o número de bolsas destinadas a pesquisadores da área da Educação. Passamos de 239 bolsas, em 2007, para os atuais 381. É bem provável que o número não seja exatamente esse, dada a dificuldade de precisar tais dados, com possíveis interrupções provocadas com o acúmulo temporário por outras bolsas, como a de pós-doutorado, mas acreditamos que não deva ser superior a 400. Mesmo assim, insuficientes para atender à demanda.

Além da disparidade na oferta de bolsas destinadas à área de Educação e às demais áreas, observamos outra controvérsia - a distribuição do CA-Educação nas diferentes regiões do Brasil. No ano de 2010, foram concedidas 120 bolsas, e a maioria se concentrava nas regiões Sul e Sudeste. A Tabela 2 evidencia, por exemplo, um aumento inexpressivo no número de vagas em relação ao ano de 2010 , entretanto, a concentração de vagas naquelas permanece a mesma.

Tabela 2. Distribuição das BP - Educação, 2011 (vigência 01/03).

\begin{tabular}{lcccccc}
\hline Região & Renova & $\%$ & Novos & $\%$ & Total & $\%$ \\
\hline CO & 0 & 0,00 & 4 & 8,33 & 4 & 3,05 \\
NE & 7 & 8,43 & 2 & 4,17 & 9 & 6,87 \\
NO & 1 & 1,20 & 1 & 2,08 & 2 & 1,53 \\
Sudeste & 53 & 63,86 & 24 & 50,00 & 77 & 58,78 \\
SUL & 22 & 26,51 & 17 & 35,42 & 39 & 29,77 \\
\hline Total & 83 & 100,00 & 48 & 100,00 & 131 & 100,00 \\
\hline
\end{tabular}

Fonte: CNPq: BPQ Elaboração própria (2013).

No ano de 2013, houve uma relativa redução na oferta de bolsas. Se, em 2011, foram oferecidas 131 bolsas, em 2013, esse valor não ultrapassou as 115. Além disso, o fluxo de bolsas abarca praticamente todas as possibilidades de renovação. Pelos dados obtidos, a maior parte das bolsas pertence ao nível Pesquisador-2, que tem renovação a cada três anos. A bolsa sênior tem renovação a cada cinco anos e o nível Pesquisador-1, a cada quatro anos. Dessa forma, como $70 \%$ das bolsas do CA-Educação estão no nível 2, é razoável que esses números estejam muito próximos da realidade. 
Constatamos que tanto o estoque de bolsas como as novas bolsas concedidas, não têm permitido que as regiões Norte, Nordeste e Centro-Oeste diminuam a desvantagem que acumularam ao longo dos anos (ver Gráfico 5).

O fluxo das mesmas demonstra que a vantagem para o Sul e Sudeste, em relação às demais regiões, nunca foi reduzida nos últimos anos, apesar do apelo das demais regiões. Se considerarmos que o incentivo à pesquisa favorece uma maior apreensão das problemáticas da educação e, por sua vez, proposições de melhorias, os dados relativos à distribuição dessas bolsas revelam uma contradição. O fato é que as maiores problemáticas em torno da educação básica residem nas regiões com menor número de bolsas.

Pela nossa contabilização, tivemos, a partir da vigência de março de 2013, um estoque de 381 bolsas. Sendo $86 \%$ das bolsas concentradas nas regiões Sul e Sudeste. Paradoxalmente, apesar de as políticas de fomento do orçamento federal, por força de lei, orientar o estímulo ao desenvolvimento das regiões fora do eixo Sul-Sudeste, as bolsas de produtividade do CA-Educação têm seguido caminho inverso. Isso está em desacordo, também, com as próprias orientações do Ministério da Ciência, Tecnologia e Inovação -MCTI.

Nesse sentido, é válido mencionar que as áreas do CNPq são agrupadas em Comitês Assessores - CAs compostos por professores integrantes do sistema de bolsas no seu nível maior (Pesquisadores-1). Esses são indicados por entidades científicas - Associação Nacional de Pós-Graduação e Pesquisa em Educação (ANPEd), Associação Brasileira de Pesquisa em Educação em Ciências (ABRAPEC), Associação Nacional de Didática e Prática de Ensino (ANDIPE), Associação Nacional de Política e Administração da Educação (ANPAE), Sociedade Brasileira de Educação Comparada (SBEC), Sociedade Brasileira de Ensino de Biologia (SBEnBio), Sociedade Brasileira de História da Educação (SBHE), Sociedade Brasileira de Educação Matemática (SBEM). Dentre essas, a ANDIPE é a única desconhecida do meio acadêmico - não possui endereço na internet e os pesquisadores da área de didática a desconhecem. Os representantes são escolhidos pelo presidente da agência.

Entretanto, o processo de escolha dos candidatos a PQ segue o fluxo das chamadas da agência, que, após recolherem os pedidos, encaminham para pareceristas ad hoc, que enviam suas opiniões quanto ao mérito. Por sua vez, servidores do CNPq alocados nas diversas áreas de conhecimento preparam relatórios que devem ser apreciados pelos Comitês Assessores, considerando critérios que se perpetuam a cada ano, em geral, assentados em 
padrões bibliométricos, e onde a análise da agência sobre temas de interesse da sociedade, necessidades regionais do sistema de Ciência, Tecnologia e Inovação tem sido pouco considerada.

Uma questão importante a destacar é que nas últimas renovações, a distribuição de novas bolsas tem priorizado as mesmas regiões e, nestas, as mesmas instituições. A concessão de novas bolsas para as regiões tem também valorizado os mesmos programas de pós-graduação. E no que diz respeito à concessão das bolsas de produtividade em pesquisa, no CA-Educação, tem-se concentrado em programas de algumas universidades, que, em alguns casos, chega a alcançar $60 \%$ dos seus membros permanentes recebendo o auxílio. Como os programas mais bem avaliados estão nas regiões Sul e Sudeste, a concentração vai se acentuando a cada ano. Entretanto, há que se destacar que os estados das regiões Norte, Nordeste e Centro-Oeste têm ampliado a sua oferta de cursos e têm programas reconhecidos como de qualidade pela CAPES.

Ramalho e Madeira (2005) fazem um amplo retrospecto sobre a expansão da pós-graduação em educação nas regiões Norte e Nordeste. Segundo eles, após a primeira etapa de fixação de mestres e doutores, entre as décadas de 1990 a 2000, é possível constatar a ampliação dos programas de pós-graduação; e, atualmente, do Amazonas a Bahia, todos os Estados tem programas de mestrado e/ou doutorado (idem). Nessa direção, os autores mencionavam, à época, que o principal desafio seria vincular a pesquisa em educação com os desafios da região, bem como atrelar os programas com perspectiva de contribuir para a melhoria dessa temática nessas regiões.

[...] Qual deve ser, pois, o compromisso das instituições de ensino superior, de seus docentes pesquisadores e de seus pós-graduandos, reunidos em grupos e linhas de pesquisa, para enfrentar o quadro exposto das disparidades e as exigências do desenvolvimento econômico, social e político? Que esperar dos programas de pós-graduação em educação, dos mestres e doutores em educação dessas regiões com tantas demandas socioeducacionais? (Ramalho; Madeira, 2005, p. 80).

Conforme Tabela 3, entre os 80 programas de mestrado e doutorado, de onde se depreende informações de pesquisadores beneficiados com bolsas, 23 estão nas três regiões (NO, NE e CO), 25 na região Sul e 32 no Sudeste. Entretanto, quando se comparam a distribuição das BP, as regiões Sul e Sudeste absorvem quase 9/10, ou seja, de cada 10 bolsas, 9 estão nas regiões Sul e Sudeste (Figura 5). 
Tabela 3. Distribuição de bolsas conforme o conceito CAPES do programa, tamanho e número médio de professores permanentes, média de teses e dissertações orientadas, bolsas de produtividade e média de PQ por professores permanentes do programa.

\begin{tabular}{lcccccc}
\hline Conceito & N. Prog. & $\begin{array}{c}\text { Tamanho } \\
\text { Programa }\end{array}$ & Prof. Perm & $\begin{array}{c}\text { Média } \\
\text { Tes/Dis }\end{array}$ & PQ & $\begin{array}{c}\text { Média de } \\
\text { PQ/PP (\%) }\end{array}$ \\
\hline 3 & 11 & 15 & 11 & 6 & 12 & 14 \\
4 & 47 & 26 & 21 & 5 & 107 & 16 \\
5 & 15 & 46 & 34 & 6 & 101 & 29 \\
6 & 4 & 42 & 34 & 7 & 66 & 58 \\
7 & 3 & 39 & 33 & 7 & 54 & 61 \\
\hline Total & 80 & 29 & 23 & 5 & 340 & 23 \\
\hline
\end{tabular}

Fonte: Coleta CAPES, 2009. Elaboração própria, (2013).

Obs: Inclui somente programas avaliados e que tenham PQ.

É possível destacar, entre os dados, que os programas com nota 6 e 7 estão nas regiões Sudeste e Sul, e onde a participação das bolsas PQ sobre os membros do programa alcança a média de $60 \%$, notadamente, influenciada pela presença dos programas do segmento privado, onde chega a alcançar $75 \%$ no número de professores do programa, com bolsa PQ. Entretanto, destacamos programas que não têm avaliação, uma vez que a bolsa é individual, representam o dobro de bolsas concedidas para os programas com avaliação 3 . Há 25 bolsas no sistema sendo concedidas a pesquisadores que não têm vinculação com universidades e programas avaliados. Dessa forma, é mais do que necessário o compartilhamento de informações entre a CAPES e o CNPq. Nesse sentido, essa cooperação deve ir além da ação conjunta desenvolvida no programa Ciência Sem Fronteiras, mas, também, sob a égide de outros programas.

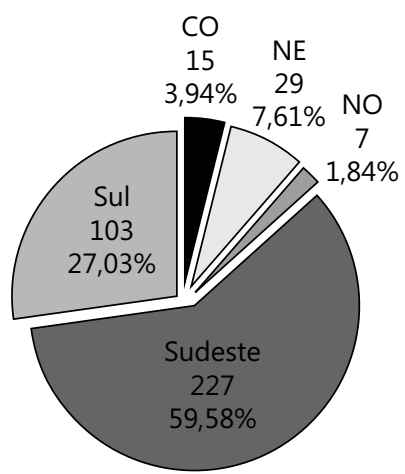

Fonte: CNPq 03/2013, BP. Elaboração própria, (2013).

Figura 5. Distribuiç̧ão de BP nas regiões do Brasil. 
Outra inquietação de nossa parte reside no fato de constatar, nas análises realizadas pelo CNPq, a ausência de informações sobre a distribuição de bolsas com os sistemas estaduais de fomento a pesquisa. Sabe-se que as regiões Sul e Sudeste, com suas agências locais, Fundação de Amparo à Pesquisa do Estado de São Paulo (FAPESP), Fundação Carlos Chagas Filho de Amparo à Pesquisa do Estado do Rio de Janeiro (FAPERJ) e a Fundação de Amparo à Pesquisa do Estado de Minas Gerais (FAPEMIG), também utilizam o sistema de bolsas para estimular as pesquisas das universidades existentes no seu território.

Dessa forma, é bem provável a existência de duplicidade de auxílios, visto que o sistema de ciência, tecnologia e inovação não possui uma base compartilhada de dados. O que demanda a unificação dos sistemas ao nível dos Estados, para poder contemplar em maior número as regiões que mais necessitam - no caso, Norte, Nordeste e Centro-Oeste.

Há que se destacar, ainda, que são exatamente nas regiões Norte, Nordeste e Centro-Oeste onde residem os maiores desafios de inclusão do sistema educacional e de desempenho da educação básica. Sobre esse aspecto, os dados divulgados pelo Índice de Desenvolvimento da Educação Básica (IDEB) denunciam essa realidade há vários anos. Apoiar com mais intensidade a pesquisa na área da educação, nessas regiões, corrobora para esse nível de educação.

\section{Considerações finais}

Tratamos de ressaltar que os Planos Nacionais de Pós-Graduação contribuíram de modo significativo para a formação de pesquisadores no Brasil. Recentemente, essa ação foi potencializada pelo processo de expansão das universidades que aderiram ao REUNI. Entretanto, o esforço empreendido para a formação de mestres e doutores ainda esta aquém da média mundial. Desta forma, ficou evidente que houve um aumento substancial dos grupos de pesquisas cadastrados nos Diretórios dos Grupos de Pesquisa do CNPq. O que demonstra um avanço na organização desses grupos nas universidades brasileiras, que passaram de 43 instituições federais, em 148 campi, para 59 instituições, em 274 campi, (Senado Federal, 2013). Porém, questionamos sobre as reais contribuições que o sistema de bolsas de produtividade tem dado para o país. Parece-nos que a concessão de bolsas baseada, notadamente, nos critérios bibliométricos não sugere um bom caminho. Tentamos retratar, em nossa reflexão, que essas bolsas parecem reproduzir uma hierarquia dificilmente suplantada, uma vez que têm privilegiado os pesquisadores que publicam, mas que pouco se conhece sobre a sua contribuição para as demandas enfrentadas pelo país. 
O sistema de PQ tem recriado o sistema de cátedra nas universidades, que, uma vez atingido pelos pesquisadores, dificilmente é modificado. Talvez tenhamos que combinar modelos desenvolvidos por outros países, que, a partir dos grupos de pesquisa, desenvolvem suas atividades considerando as demandas e problemas da atualidade. A simples concessão de bolsas baseada em critérios e desejos individualizados parece reproduzir um processo excludente, principalmente agora, com a chegada de um contingente significativo de novos professores às universidades públicas federais. $\mathrm{O}$ modelo vigente não tem espaço para absorver os novos pesquisadores, porque não tem escala suficiente, o que remete à necessidade de reforçar o papel dos grupos de pesquisa e a ampliação dos seus recursos, fato que corroboraria para a inserção desses novos pesquisadores e, consequentemente, a vinculação de seus respectivos projetos às linhas de pesquisa dos programas de pesquisa das universidades, o que favoreceria uma maior articulação com a educação básica e a melhor fixação dos pesquisadores nos campi distantes das capitais.

Nesse sentido, torna-se premente fortalecer um sistema de PQ baseado também nos grupos de pesquisa. Visto que alguns beneficiários de $\mathrm{PQ}$ não se vinculam de forma orgânica aos programas de pós-graduação, são apenas colaboradores, e cultuam uma espécie de "notoriedade" por aquilo que produziram no passado. Entretanto, se desconhece sua atual contribuição, a partir do apoio dado pelo sistema de PQ para a formação de novos quadros e para o enfrentamento das necessidades educacionais do país. O sistema privilegia o estoque pretérito e não vincula a produção aos objetivos da mesma. O trabalho de Wainer e Vieira (2013) mostra que o critério é exclusivamente bibliométrico.

Outra questão abordada é a de que a pesquisa deve contribuir para o enfrentamento das problemáticas do país. E, sobretudo, na área de Educação, uma das áreas prioritárias para o desenvolvimento de qualquer nação. Mencionamos que a educação básica padece de uma série de problemáticas que impactam na efetividade dessa política e, consequentemente, no êxito dos alunos. Ficou evidente a ausência dessa orientação na distribuição das bolsas do CNPq, pois, no CA de Educação, existe um descompasso abissal entre as regiões. Apesar da elevação significativa no número de grupos de pesquisas da região Norte - em 1993, havia 70 grupos e, hoje, contempla 1.400, ou seja, foi ampliado em 20 vezes, - ainda é uma das regiões que apresenta baixos índices no que tange à educação básica. O número representativo desses beneficiados, com bolsas, que não têm vinculação com grupos de pesquisa evidencia, também, a ausência de um plano estratégico de impacto nacional, por parte do CNPq e, consequentemente, não representa uma intervenção direta para a educação básica. 
E como se tudo isso não fosse suficiente, há uma tendência de migração de professores da educação básica, quando da conclusão dos cursos de pós-graduação stricto sensu, para o Ensino Superior, deixando também de contribuir para mudanças na educação básica.

Reiteramos a discussão sobre a necessidade de se vincular à produção de conhecimento e o sistema de fomento às demandas reais da educação básica. Premissa que demanda o aprofundamento desse estudo, ou seja, avaliar o real impacto da Bolsa de Produtividade, visando entender em que medida as referidas bolsas têm gerado mudanças no âmbito da educação básica. Para tanto, seria condizente a realização de um estudo longitudinal, para avaliar o impacto da ação dos pesquisadores/professores nos seus estabelecimentos de ensino, desde seu ingresso no sistema de $\mathrm{PQ}$, sua participação nos referidos programas, com o estabelecimento de um protocolo de compromisso que contemple a devolutiva de seu avanço/conhecimento para a educação básica. Essa proposição daria maior visibilidade à área de educação, área esta que apresenta maior crescimento no ingresso de mestres e doutores no país; e, consequentemente, é a que demanda maior inversão. Portanto, faz-se necessária a ampliação do número de bolsas PQ em Educação, com uma distribuição mais equitativa das vagas, considerando, para tanto, alguns critérios: vinculação das ofertas com as regiões que demandam maior inversão, estabelecimento de indicadores de impacto social para todas as áreas e, sobretudo, para as bolsas do CA-Educação, e maior visibilidade sobre a distribuição das mesmas. Portanto, torna-se premente o reordenamento das prioridades no sistema de apoio à pesquisa, tendo como base outro modelo que não o de bolsas individualizadas. 


\section{Researchers' formation in education in Brazil, the role of agencies and basic education}

\section{Abstract}

This paper includes a discussion about the distribution process of the Research Productivity Scholarships from CNPq. This work is based on a description of the evolution of graduate programs in Brazil, in particular, those related to the education area. The contribution of these programs to basic education is discussed and the scholarship system productivity is identified as a way to stimulate this relationship. Lack of transparency in the distribution process and excessive concentration in certain regions of the country validate the importance of strengthening the role of research groups and of redefining new selection criteria to distribute, considering the demands of the new National Education Plan.

Keywords: Research in education. Productivity scholarship. Basic education. Graduate.

\section{Formación de investigadores en educación en Brasil, el papel de las agencias y la educación básica}

\section{Resumen}

Este texto contiene una reflexión sobre el proceso de distribución de las Becas de Productividad en Investigación del CNPq y se apoya en una descripción sobre la evolución de los programas de posgrado en el país, en particular, del área de educación. Con eso, problematiza la contribución de estos programas a la educación básica, e identifica que una de las maneras de motivar dicha relación es el sistema de Becas de Productividad. Sin embargo, argumenta que la escasa nitidez sobre el proceso de distribución de estas becas y su excesiva concentración en ciertas regiones del país, hacen necesario un mayor papel de los grupos de investigación y una redefinición de nuevos criterios de distribución de estas becas, considerando las demandas del nuevo Plan Nacional de Educación.

Palabras clave: Investigación educativa. Becas de productividad. Enseñanza básica. Postgrado. 


\section{Referências}

ANDRÉ, M. Formação de professores: a constituição de um campo de estudos. Educação, Porto Alegre, v. 33, n. 3, p. 174-181, set./dez. 2010.

BOLETIM estatístico de pessoal e informações organizacionais, Brasília, DF, v. 19, n. 216, abr. 2014.

BRASIL. Câmara dos Deputados. Projeto de Lei no 6.840/2013 (Da Comissão Especial destinada a promover estudos e proposições para a reformulação do ensino médio). Brasília, DF, 2013b). Disponível em: http://www.camara. gov.br/proposicoesWeb/prop_mostrarintegra?codteor $=1200428 \&$ filename $=$ PL+6840/2013. Acesso em: 4 maio 2015.

. Instituto Nacional de Estudos e Pesquisas Educacionais Anísio Teixeira - INEP. Censo da educação superior. Brasília, DF: 2012. Disponível em: $<$ http://portal.inep.gov.br/web/censo-da-educacao-superior $>$. Acesso em: 04 mai. 2015.

. Lei n $\mathrm{n}^{\circ}$ 9.394, de 20 de dezembro de 1996. Estabelece as diretrizes e bases da educação nacional. Diário Oficial da União, Brasília, DF, 23 dez. 1996.

. Lei $\mathrm{n}^{\circ} 11.502$, de 11 de julho de 2007. Modifica as competências e a estrutura organizacional da fundação Coordenação de Aperfeiçoamento de Pessoal de Nível Superior - CAPES, de que trata a Lei no 8.405, de 9 de janeiro de 1992; e altera as Leis nos 8.405, de 9 de janeiro de 1992, e 11.273, de 6 de fevereiro de 2006, que autoriza a concessão de bolsas de estudo e de pesquisa a participantes de programas de formação inicial e continuada de professores para a educação básica. Diário Oficial da União, Brasília, DF, 12 jul. 2007.

. Lei $\mathrm{n}^{\circ} 13.005$, de 25 de junho de 2014. Aprova o Plano Nacional de Educação - PNE e dá outras providências. Diário Oficial da União, Brasília, DF, 26 jun. 2014a;Edição extra.

. Ministério da Ciência, Tecnologia e Inovação. CNPq. Investimentos do CNPq em CT\&I. Brasília, DF, 2014b. Disponível em: $<$ http://fomentonacional. cnpq.br/dmfomento/home/fmthome.jsp>. Acesso em: 4 maio 2015.

. Ministério da Educação. Coordenação de Aperfeiçoamento de Pessoal de Nível Superior. Plano Nacional de Pós-Graduação (PNPG) 2011-2020. Brasília, DF, 2010. v. 1. Disponível em: $<$ http://tinyurl.com/ pwka6ym>. Acesso em: 22 ago. 2013. 
BRASIL. Senado Federal. Educação: salto de qualidade é urgente. Em Discussão, Brasília, DF, v. 4, n. 14, fev. 2013. Disponível em: http://migre.me/ pZp9g. Acesso: 04 mai. 2015.

CONSELHO FEDERAL DE EDUCAÇÃO. Parecer CFE nº 977/1965, aprovado em 3 dez. 1965. Revista Brasileira de Educação, Rio de Janeiro, n. 30, p.162-173, set.-dez. 2005. doi:10.1590/S1413-24782005000300014

CENTRO DE GESTÃO E ESTUDOS ESTRATÉGICOS. Mestres 2012: Estudos da demografia da base técnico-científica brasileira. Brasília, DF, 2012. . Doutores 2010: estudos da demografia da base técnico-científica brasileira. Brasília, DF, 2010.

CUNHA, C. (2012). A universidade e a crise de qualidade da educação básica. In C. CUNHA, J. V. SOUSA, \& M. A. SILVA (Orgs.), Universidade e educação básica: políticas e articulações possiveis (pp. 1-26). Brasília, DF: Faculdade de Educação UNB.

CURY, C. R. J. Quadragésimo ano do parecer CFE n 977/65. Revista Brasileira de Educação, Rio de Janeiro, n. 30, p. 7-20, set.-dez. 2005. doi:10.1590/S1413-24782005000300002

DUTTA, S.; LANVIN, B. (Eds.). The Global Innovation Index 2013: the local dynamics of innovation. Geneve: Cornel University, Word Intellectual Property, 2014. Disponível em: $<\mathrm{http}: / /$ www.wipo.int/ export/sites/www/freepublications/en/economics/gii/gii_2013.pdf $>$. Acesso em: 15 abr. 2014.

FERREIRA, E. Políticas para a educação básica no Brasil e as trilhas incertas da justiça social. In: CUNHA, C.; SILVA, M.A. (Orgs.). Educação básica: políticas, avanços e pendências. Campinas: Autores Associados, 2014. p.121-47.

GATTI, B.A. Avaliação e qualidade do desenvolvimento profissional docente. Avaliação, Sorocaba, v. 19, n. 2, p. 373-84, jul. 2014.

. Educação, escola e formação de professores: políticas e impasses. Educar em Revista, Curitiba, n. 50, p. 51-67, out./dez. 2013.

Reconhecimento social e as políticas de carreira docente na educação básica. Cadernos de Pesquisa, São Paulo, v. 42, n. 145, p. 88-111 jan./abr. 2012. 
GATTI, B.A. et al. Programa de Pesquisa para o Sistema Nacional de Educação: ações compartilhadas. 2015. Disponível em: <http://migre.me/ pTuGd>. Acesso em: 29 abr. 2015.

HOSTINS, R.C.L. Formação de pesquisadores em programas de excelência de pós-graduação em educação. Revista Brasileira de Educação, Rio de Janeiro, v. 18, n. 53, p. 415-34, abr.-jun. 2013. doi:10.1590/S1413-24782013000200010

HOUZEL, S. H. O CNPq não acha meu trabalho digno de financiamento! Jornal da Ciência, Rio de Janeiro, JC e-mail 4656, de 30 de janeiro de 2013. Disponível em: $<\mathrm{http}: / / \mathrm{www}$.jornaldaciencia.org.br/Detalhe.jsp?id=85638>. Acesso em: 19 mar. 2013.

INSTITUTO BRASILEIRO DE GEOGRAFIA E ESTATÍSTICA - IBGE. Censo demográfico 2010: resultados gerais da amostra. Rio de Janeiro, 2012. Disponível em: <ftp://ftp.ibge.gov.br/Censos/Censo_Demografico_2010/ Resultados_Gerais_da_Amostra/resultados_gerais_amostra.pdf $>$. Acesso em: 4 maiO 2015.

JUSTINO, D. Dificil é educá-los: o atraso da educação e a urgência em se refletir sobre o seu futuro. Lisboa: Fundação Francisco Manuel dos Santos, 2010.

MACEDO, E.; SOUSA, C.P. A pesquisa em educação no Brasil. Revista Brasileira de Educação, Rio de Janeiro, v. 15, n. 43, p. 166-76, jan./abr. 2010. doi:10.1590/S1413-24782010000100012

MARTINS, Z. et al. Pós-graduação e educação básica brasileira: uma iniciativa da CAPES para subsidiar a política de fomento da rede pública dos professores de educação básica. Momento: Diálogos em Educação, Rio Grande, v. 20, n. 2, p. 81-92, maio 2012.

MENEZES, L.C. Pós-graduação e educação básica no Brasil - um depoimento e uma proposta. In: CUNHA, C.; SOUSA, J.V.; SILVA, M.A. (Orgs.). Universidade e Educação Básica: políticas e articulações possíveis. Brasília, DF: Faculdade de Educação/UnB, 2012. p. 259-66.

NOVOA. Antonio. Políticas para o ensino superior: Inovações pedagógicas no processo de ensino e aprendizagem. Academia Nacional de Professores: ESPM, 12 de novembro de 2013, 22p (online). Disponível em: http://goo.gl/ j3p9sM 
RAMALHO, B.L.; MADEIRA, V.P.C. A pós-graduação em educação no Norte e Nordeste: desafios, avanços e perspectivas. Revista Brasileira de Educação, Rio de Janeiro, n. 30, p. 70-81, set.-dez. 2005. doi:10.1590/S1413-24782005000300006

SILVA, M.A.S. Dimensões da política do banco mundial para a educação básica pública. In: CUNHA, C..; SILVA, M.A..(Orgs.). Educação básica: políticas, avanços e pendências. Campinas: Autores Associados, 2014. p. 57-96.

SOARES, A.S. A formação do professor da Educação Básica entre políticas públicas e pesquisas educacionais: uma experiência no Vale do Jequitinhonha em Minas Gerais. Ensaio: Avaliação e Politicas Púbicas em Educação, Rio de Janeiro, v. 22, n. 83, p. 443-64, abr./jun. 2014. doi:10.1590/S0104-40362014000200008

VELOSO, F., et al. (Org.). Educação básica no Brasil: construindo o país do futuro. Rio de Janeiro: Campus, 2009.

WAINER, J.; VIEIRA, P. Avaliação de bolsas de produtividade em pesquisa do CNPq e medidas bibliométricas: correlações para todas as grandes áreas. Perspectivas em Ciência da Informação, v. 18, n. 2, p. 60-78, abr./jun. 2013. doi:10.1590/S1413-99362013000200005

\section{Informações do autor}

Remi Castioni:Doutorado em Educação, Universidade Estadual de Campinas - Unicamp. Professor e pesquisador da UnB. Contato: rcastioni@globo.com 